\title{
Correspondence
}

\section{The Health of the Nation and suicide prevention}

Sir: The Health of the Nation (Department of Health, 1992) envisages a significant reduction in suicide rates by the year 2000 . However, official suicide rates may not be a valid indicator of a nation's mental health. First, there are a multiplicity of variables that influence suicide rates, of which psychiatric factors are only one. Second, official suicide rates underestimate the true numbers of people who kill themselves. Furthermore, we would argue that the targets set fail to take account of the complexity of suicide prevention.

Is has been suggested that one way of achieving Health of the Nation targets is identification of people who are considered to be 'at-risk' for suicide. There are, however, general principles in relation to screening that need to be considered. Screening has resource implications which can only be warranted if manifest benefit can be demonstrated. A prerequisite of effective screening instruments is that they should demonstrate acceptable specificity and sensitivity. As yet, however, no such instrument exists. In one study, for example, (Nordentoft et al, 1993) risk factors for suicide taken in combination had a sensitivity of $60 \%$ and a specificity of $61 \%$. It follows that screening for at-risk cases would currently result in unacceptable numbers of both 'false positives' and 'false negatives'. In addition, for screening programmes to be worthwhile there should be good evidence that intervention subsequent to the identification of the target population is effective. However, subgroups of people who are identified in studies as being at-risk for suicide typically include people with personality disorders, substance abusers, the socially isolated and the unemployed. The effectiveness or appropriateness of psychiatric intervention among these sub-groups is, at best, uncertain.

It is a straightforward task to ascertain official suicide rates and set targets for their reduction. There are strategies that may help to reduce suicide numbers, such as improved detection and management of depressive illnesses (Rutz et al, 1989) and the use of antidepressant drugs that are less toxic in overdose. We believe, however, that there should be more debate with regard to the feasibility of achieving the Health of the Nation goals. If, by the year 2000 these targets have not been realised, this may not be due to failure on the part of clinicians, but rather that the goals set were unrealistic in the first place.

DepartMENT of HEALTH (1992) The Health of the Nation strategy for health in England. London: HMSO. (Cmnd 1986).

NORDENTOFT, M., BREUM, L., MUNCK, L.K., NORDESTGaARD, A.G.. et al (1993) High mortality by natural and unnatura causes: a 10 year follow up study of patients admitted to a poisoning centre after suicide attempts. British Medical Journal, 306, 1637-1641.

RUTZ, W., vON KNORRING, L. \& WALINDER, J. (1989) Frequency of suicide on Gotland after systematic postgraduate education of general practitioners. Acta Psychiatrica Scandinavica, 80, 151-154.

Elisabeth A. ASHBRIDGe and STEVEN Milne, St Nicholas Hospital, Jubilee Road, Gosforth, Newcastle upon Tyne NE3 3XT

\section{Prevention in psychiatry}

Sir: The authors of the Report of the Special Committee on the Place of Prevention in Psychiatry (CR21, Royal College of Psychiatrists, 1993) deserve to be commended for their balanced and thoughtful approach. In particular their conclusion that "evidence is not yet avallable to justify a large diversion of treatment resources to prevention ..." (Paykel, 1993) should be remembered by all those involved in the management and planning of patient care.

It is vital that psychiatrists resist the overly prescriptive view that there are certain ideal lifestyles and forms of social existence which are 'better' at preserving mental health than others. Not only does this invite a return to more paternalistic practice but, as the report shows, is often tendentious. We must continue to allow patients to follow their own lifestyles and base our advice and intervention only on scientifically proven preventive measures. To interfere in patients' everyday existence is a responsibility which should never be taken lightly, especially on the basis of unresearched speculative theories.

PAYKEl, E.S. (1993) Prevention in psychiatry. Psychiatric Bulletin. 17, 633.

JOHN COATES, Belfast City Hospital, Belfast BT9 $7 A B$

\section{Working in a child guidance clinic}

Sir: I was interested to read the letter by Jan Hermsen on 'Working In A Child Guidance Clinic' (Psychiatric Bulletin, 1993, 17, 626). I did my six 